\section{BENEFITS OF THYMECTOIMY IN MYASTHENIA GRAVIS}

KEY WORDS: Extended

Thymectomy, Follow-up, Myasthenia Gravis, Thoracoscopic Thymectomy
Dr Manoj M Joshi

\section{Dr Hrishikesh}

\section{Parashi*}

\section{DrVignesh} Ravikumar
M. S, M. Ch, Dept Of Cardio Vascular Thoracic Surgery ,grant Govt Medical College \& Sir JJ Group Of Hospitals, Mumbai.

M. S, M. Ch, Dept Of Cardio Vascular Thoracic Surgery ,grant Govt Medical College \& Sir JJ Group Of Hospitals, Mumbai. *Corresponding Author

M. S, M. Ch, Dept Of Cardio Vascular Thoracic Surgery ,grant Govt Medical College \& Sir JJ Group Of Hospitals, Mumbai.

In recent years, thymectomy has become a widespread procedure in the treatment of myasthenia gravis (MG). Likelihood of remission was highest in preoperative mild disease classification (Osserman classification $1,2 \mathrm{~A}$ ). In absence of thymoma or hyperplasia, there was no relationship between age and gender in remission with thymectomy. In MG treatment, randomized trials that compare conservative treatment with thymectomy have started, recently. As with non-randomized trials, remission with thymectomy in MG treatment was better than conservative treatment with only medication. There are four major methods for the surgical approach: transcervical, minimally invasive, transsternal, and combined transcervical transsternal thymectomy. Transsternal approach with thymectomy is the accepted standard surgical approach for many years. In recent years, the incidence of thymectomy has been increasing with minimally invasive techniques using thoracoscopic and robotic methods. There are not any randomized, controlled studies which are comparing surgical techniques. However, when comparing non-randomized trials, it is seen that minimally invasive thymectomy approaches give similar results to more aggressive approaches.

\section{INTRODUCTION}

Myasthenia gravis is an autoimmune disorder that affects the postsynaptic acetylcholine receptors of voluntary muscle and results in weakness and fatigue of the affected muscle group. ${ }^{1,2}$ Medical treatment involves the use of anticholi nest erase agents, immunosuppressive drugs, plasmapheresis and gammaglobulin, with reported complete clinical remission rates (CCRRs) of only $15 \%{ }^{2}$

A relationship between the thymus and myasthenia gravis was demonstrated in 1901; but it was Blalock et $\mathrm{al}^{3}$ in 1939 who first demonstrated the beneficial effect of thymectomy4. since then thymectomy has become an increasingly accepted procedure in the treatment of myasthenia gravis, as it can achieve complete clinical remission rates as high as $80 \%$ in accordance with most of the reports published in the literature. ${ }^{5-7}$ However controversy still persists regarding appropiate selection of patients, the optimal surgical approach, and the extent of mediastinal dissection required. ${ }^{1,8}$ The purpose of the present study was to assess the results obtained by thymectomy for myasthenia gravis in a series of 57 patients, quantify the degree of clinical improvement following thymectomy by assessing changes in both stage and medication requirement and to identify prognostic factors that may be useful in deciding optimal patient selection.

\section{MATERIAL AND METHODS}

The study group comprises of 57 patients with myasthenia gravis who were admitted in Grant Govt Medical College and Sir JJ Hospital, Mumbai and underwent trans-sternal total thymectomy during the period of January 2000 to December 2007.

Each patient was evaluated before surgery by the neurologist and diagnosis was based on clinical signs and symptoms, positive response to edrophonium chloride test, and electromyography test. All patients underwent clinical staging based on the modified Osserman classification.

Indications for surgical therapy included persistent gener alized myasthenia gravis while on medical regimen, pers istent ocular myasthenia gravis under appropriate med ic ation and presence of a thymoma as diagnosed by computed tomography. Before surgery each patient underwent routine chest $\mathrm{x}$ - ray, and computed tomography of chest. Laboratory studies included radioimmunoassay for the acetylcholine receptor antibody level, immunoglobulin level, serum

complement test, thyroid function test and serum studies for antithyroid antibodies.

All 57 patients underwent median sternotomy and transsternal thymectomy. All thymic tissue and anterior mediastinal fat were removed from the lower limit of the pericardium inferiorly to the cervical thymic extension superiorly and from one phrenic nerve to the other. Attempts were made to remove all involved tissue in the patients with invasive thymoma.

Surgical procedures were performed using general anae s thesia. Following surgery, all the patients were managed in an intensive care unit and were maintained on mechanical ventilation. All patients who had received anticholinesterase inhibitor (AchEI) prior to surgery received these agents one hour prior to extubation.

Recorded preoperative data included age, sex, Osserman stage, medication requirement, laboratory studies, duration of disease and coexistent medical

conditions. Following surgery, the time to extubation, thymic abnormality, complications and length of hospitalization were recorded.

After discharge patients were followed up at varying inte rvals; the mean follow up was 2.4 years. All patients were interviewed by a neurologist and explicit details of exercise tolerance, employment, Osserman stage, medication requirement, complications and follow-up duration were recorded.

Patients response to thymectomy was graded according to Milichat and Dodge criteria of follow up.

A) Complete clinical remission of symptoms and off anticho linesterace inhibitor for more than 90 days. 
B) Significant clinical improvement with decreased medi cation.

C) Moderate clinical improvement with medication.

D) No improvement or unchanged stable clinical status.

E) Clinical worsening on same dosages of medication or increased dosages (requires new medication).

Statistical analysis of data was done using the Fisher exact test and analysis of variance, with $p<0.05$ was considered signif icant.

\section{RESULTS}

57 patients underwent thymectomy at Grant Govt Medical College \& Sir JJ Hospital,Mumbai. Thirty-two patients (56.1\%) were male and twenty-five $(43.9 \%)$ female aged between 8 and 59 years. The mean age was 33.3 years. Application of Ossermans classification yielded the following as shown in (table 1) grade I-9 patients; grade IIA-27patients; grade IIB 14 patients, grade III- 5 patients and grade IV- 2 patients.

Time elapsed from diagnosis to operation was 2 years in 42 patients $(73.70 \%)$ and more than 2 years in 15 patients (26.30\%).Before thymectomy 20 patients were on antichol in estrase agents, 3 on corticosteroids, 5 on anticholinestrase and steroids, 15 on anticholinestrase and immunosuppresants and 14 patients were on combined regimen of the drugs and had undergone plasmapheresis. There was 3.5\% (2 patients) mortality in hospital, both patients belonged to Ossermans grade IIb and had myas thenic crisis. One patient developed disseminated intrav as cular coagulation, Septicaemia and expired on the 5 th post-operative day. The second patient needed tracheostomy and prolonged ventilation, with multiple cycles of plasmapheresis and steroids but the patient expired on the 108th post-operative day. There is no late postoperative death on followup. 3 patients had postoperative complications ( 1 right sided pneumothorax, l Left Lower Lobe pneumonia, l surgical wound infection). Late complication on follow up were present in 2 patients, ( 1 patient had recurrence of thymoma 3 months after surgery, 1 discharging sinus over sternal region). 10 patients had severe myasthenic crisis postoperatively. They were intubated, ventilated, treated with multiple cycles of plasmapheresis, prednisolone and anticholinestrase agents. Of these 5 are in remission, 3 patients had improvement $\& 2$ patients expired as already discussed in mortality. Post-operative pathologic study of the thymus revealed hyperplasia of thymus in 21 patients $(36.8 \%)$, thymoma in 12 patients $(21.1 \%)$ including a case of thymic carcinoma, atrophy in 5 patients $(8.8 \%)$, normal thymus in 19 patients (33.3\%).

In the present study 13 patients (20.6\%) had associated comorbid disease along with myasthenia gravis. 5 patients had coexisting autoimmune disease (3 Patients had thyrotoxicosis, 1 patient had systemic lupus erythematosis and choloquine induced keratopathy, 1 patient had antiphospholipid antibody syndrome), 5 patients had steroid induced Cushings disease, 1 patient had steroid induced diabetes mellitus, 1 patient had hypertension, and 1 patient had pulmonary tuberculosis. The mean hospital stay in the present study was 15 days with 3 patients having prolonged hospital stay due to complications. Follow up ranged from 6 months to 9 years. Mean follow up is 2.4 years. According to Milichat and Dodge criteria, 31 patients $(54.4 \%)$ had complete clinical remission, $9(15.8 \%)$ had clinical improvement, $12(21.1 \%)$ had no improvement, 3 patients $(6.3 \%)$ worsened after thymectomy \& 2 (3.5\%) patients expired. With respect to correlation of the prognostic factor to complete clinical remission, it is noteworthy that 17 female patients achieved complete clinical remission as compared to 14 male patients. Thus, female sex had better outcome after thymectomy $(p=0.04)$

In the present study, age, histopathological characteristic of the excised thymus and duration of disease did not correlate with the outcome after thymectomy for myasthenia gravis. However, large number of studies have shown that myasthenic patients with younger age were significantly more likely to benefit from thymectomy than older age, hyperplastic excised thymus and shorter duration from onset of disease to surgery are associated with better clinical response after thymectomy for myasthenia gravis. The surgical outcome of patients in different Osserman stages were analysed. Most of the patients who achieved complete clinical remission belonged to Osserman stage I, IIA \& III $(P=0.021)$ (Table 2$)$. The study further demonstrated decreasing response to surgery with incre asing Osserman stage $(\mathrm{P}=0.007)$.

Post-operative medication requirement was recorded at the time of last followup. (Table 3). In general, patients continued receiving the minimal dose necessary to control symptoms effectively and were weaned off medications as tolerated. A significant correlation was found between outcome and postoperative medication requirement $(p=0.001)$ indicating, medication requirement decrease after thymectomy.

\section{Table 1}

\begin{tabular}{|l|l|l|}
\hline Class & No of patients & $\%$ \\
\hline I & 9 & 15.78 \\
\hline IIA & 27 & 47.36 \\
\hline IIB & 14 & 24.56 \\
\hline III & 5 & 8.77 \\
\hline IV & 2 & 3.50 \\
\hline
\end{tabular}

Table 2 Osserman

\begin{tabular}{|l|l|l|l|l|l|l|}
\hline Class & $\begin{array}{l}\text { No of } \\
\text { patients }\end{array}$ & $\begin{array}{l}\text { Remission } \\
\text { Improvement }\end{array}$ & $\begin{array}{l}\text { No } \\
\text { Improvement }\end{array}$ & Worse & Death \\
\hline I & 9 & 5 & 1 & 3 & - & - \\
\hline IIA & 27 & 18 & 6 & 2 & 1 & - \\
\hline IIB & 14 & 4 & 2 & 4 & 2 & 2 \\
\hline III & 5 & 4 & - & 1 & - & - \\
\hline IV & 2 & - & - & 2 & - & - \\
\hline
\end{tabular}

Table 3. Medication requirement

\begin{tabular}{|l|l|l|l|}
\hline No & Drugs & Before Surgery & After Surgery \\
\hline 1 & Pyridostigmine & 20 & 8 \\
\hline 5 & $\begin{array}{l}\text { Pyridostigmine + } \\
\text { Azathioprin 15 }\end{array}$ & 15 & 8 \\
\hline 9 & Combination + pheresis & 14 & 10 \\
\hline 4 & Steroids & 3 & - \\
\hline 5 & $\begin{array}{l}\text { Pyridostigmine + } \\
\text { steroids }\end{array}$ & 5 & - \\
\hline 6 & None & - & 31 \\
\hline
\end{tabular}

\section{DISCUSSION}

Thymectomy for myasthenia gravis had its origin in 1939 when Alfred Blalock \& associates successfully resected the thymus containing a thymic cyst from a 26-year-old woman with myasthenia gravis. ${ }^{3}$ Myasthenia gravis is an autoimmune disease impairing neuromuscular transmission because of binding of antibo dies to acetylcholine receptors. ${ }^{2}$ The condition may affect any age group, with peak incidence in women in their thirties \& forties and men aged between sixties and seventies. ${ }^{1}$ Initially involved site is most often the eye with about $80 \%$ experiencing generalized muscular weakness. ${ }^{1}$ Medical treatment for myasthenia gravis consist of anticholinesterase agents, steroids, immunosuppressive \& plasmapheresis to reduce serum antibody concentration. A complete clinical remission rate as low as $15 \%$ after medical treatment has been reported. ${ }^{2,6,9}$ Surgical treatment has become an increasingly accepted procedure resulting in complete clinical remission rate as high as $42 \%$ and clinical

improvement in up to $94 \%$ cases. ${ }^{7,10-12}$ Trans sternal approach for thymectomy is thestandard procedure and we followed to extirpate all the thymic tissue including the adipose tissue at 
the anterior mediastinum, as there is existence of thymic tissue outside the capsule of the proper thymus. ${ }^{13,14}$ A number of factors influencing success of thymectomy for myasthenia gravis have been reported. Most studies have described greater improvement in female patients. ${ }^{7,10,15-17}$ Our results agree with these studies. In the present study, age did not correlate with the outcome although reported literature suggests young adults have higher complete clinical remission rate. ${ }^{5,8,18}$ Preoperative stage was evaluated as a prognostic factor. In the present study, patients in stage I, IIA \& III exhibited significantly greater degree of post-operative clinical improvement than stage IIB and IV. Several previous investigators have examined the influence of preoperative Ossermann stage on the degree of clinical post thymectomy improvement and have shown mixed results. Maggie et $\mathrm{al}^{19}$ reported $51 \%$ remission rate in IIA disease \& $40 \%$ in IIB. Papatestas et $\mathrm{al}^{9}$ showed greater improvement in patient with mild generalized symptoms. Other investigators have been unable to show a significant difference in the results with preoperative stage. $^{20}$

Myasthenia gravis with ocular involvement remains a controversial indication for thymectomy. ${ }^{21}$ Untreated, 2/3rd of them will develop generalized myasthenia gravis. Papatestas and colleague ${ }^{9}$ Masaoka and associates ${ }^{14}$ unequivocally advocate thymectomy for ocular myasthenia gravis. We also recommend thymectomy for ocular myasthenia gravis. Pathologic study of thymus after thymectomy has been reported to closely relate to outcome. Hyperplastic thymus has been associated with higher complete clinical rate ${ }^{6,10,22}$ In the present study pathology did not correlate with the outcome. Our conclusion, that the patient with thymoma did not show a poor response to thymectomy than those with non-neoplastic thymus gland is in agreement with the findings of Olanow and colleagues. ${ }^{11}$

Medication requirement in patients of myasthenia gravis decreases significantly after thymectomy. ${ }^{1}$ Our study fully agrees with these finding, and there is strong relation between thymectomy and reduced postoperative medication requirement. In summary, on the basis of our results we conclude that thymectomy is a beneficial procedure for myasthenia gravis patients with $70.2 \%$ patients getting benefited from surgery and median survival has been $97 \%$ at 1 year $(95 \% \mathrm{CI}=82 \%-112 \%)$ (Fig 1.). Female sex, and mild to moderate generalized myasthenia gravis

are the main prognostic factor determining the outcome. Medication requirement decreases post-operatively. We also advocate thymectomy for ocular myasthenia gravis.

\section{REFERENCES}

1. Blossom GB, Ernstoff RM, Howells GA, Bendick PJ, Glover JL. Thymectomy for myasthenia gravis. Arch Surg 1993; 128:855-62.

2. Nieto IP, RobledoJPP, Pauelo MC, et al. Prognostic factor for myasthenia gravis treated by thymectomy; Review of 61 cases. Ann Thorac Surg 1999; 67: 1568-71.

3. Blalock A, Mason MF, Morgan HJ, Riven SS : Myasthenia gravis and tumors of thymic region: report of a case in which the tumor was removed. Ann Surg 1939; 110:544-61.

4. Krischner PA. Alfred Blalock and thymectomy for myasthenia gravis. Ann Thorac Surg 1987; 43:348-49.

5. Clark RE, Marbarger JP, West PN, et al. Thymectomy for myasthenia gravis in the young adult. Long-term results. J Thorac Cardiovasc Surg 1980; 80: 696-701.

6. Rubin JW, Ellison RG, Moore HV, Pai GP. Factors affecting response to thymectomy for myasthenia gravis. J Thorac Cardiovasc Surg 1981; 82: 720-28.

7. Faulkner SL, Ehyai A, Fisher RD, Fenichel GM,Bender HW Jr. Contemporary management of myasthenia gravis. The clinical role of thymectomy. Ann Thorac Surg 1977;23:348-52.

8. Venuta F, Rendina EA, De Giacome T, et al.Thymectomy for myasthenia gravis ;a 27-year experience.EuroJ Cardiothorac Surg 1999; 15:621-25.

9. Papatestas AE, Genkins G, Kornfeld P, et al. Effects of thymectomy in myasthenia gravis. Ann Surg 1987;206:79-88.

10. Hatton PD, Diehl JT, Daly BD, et al. Trans sternal radical thymectomy for myasthenia gravis:A 15 years review. Ann Thorac Surg 1989;47:838-40.

11. Olanow LW, Wechsler AS, Roses AD. A prospective study of thymectomy and serum acetylcholine receptor antibodies in myasthenia gravis. Ann Surg 1982;196:113-21.

12. First WH, Thirunalai S, Doehring $\mathrm{CB}$, et al. Thymectomy for the myasthenia gravis patients: factots influencing outcome. Ann Thorac Surg 1994; 57: 334-38.

13. Masaoka A, Yutaka Nagaoka Y, Katakey. Distribution of thymic tissue at the anterior mediastinum. Current procedure in thymeetomy. J Thorac Cardiovasc Surg 1975; 70:747-54.

14. Masaoka $A$, Yamakawa Y, Niwa $\mathrm{H}$, et al . Extended thymectomy for myasthenia gravis patient; A 20 year review. Ann Thorac Surg 1996;62:853-59.

15. Cohn HE, Solit RW, Schatz NJ, Schlezinger N. Surgical treatment in myasthenia gravis.A 27 year experience.J Thorac Cardiovasc Surg 1974;68:876-85.

16. Jaretzki A 3rd, Penn AS, Younger DS, et al. Maximal thymectomy for myasthenia gravis. Results.JThorac Cardiovasc Surg 1988;95: 747-757.

17. Mulder DG, Herrmann C,Jr, Keesey J,Edwards H. Thymectomy for myasthenia gravis.Am J Surg 1983; 146:61-66.

18. Budde JM, Morris CD, Gal AA, Mansour KA, Miller JI. Jr. Predictors of outcome in thymectomy for myasthenia gravis. Ann Thorac Surg 2001;72:197-202.

19. Maggi G, Casadio C, Cavallo A, Cianci R. Molinatti M, Ruffini E. Thymectomy in myasthenia gravis:results of 662 cases operaterd upon in 15 years. Eur J Cardiothorac Surg 1989; 3:504-09.

20. Spath G, Brinkmann A, Huth C, Wietholter H. Complications and efficacy of transsternal thymectomy in myasthenia gravis.Thorac Cardiovasc Surg 1987; 35:283-89.

21. Roberts PF, Venuta F, Rendina E, et al. Thymectomy in the treatment of ocular myasthenia gravis.JThorac Cardiovasc Surg 2001; 122:562-68.

22. Buckingham JM, Howard FM Jr, Bernatz PE, et al. The value of thymectomy in myasthenia gravis :a computer assisted matched study. Ann Surg. 1976; 184 $453-58$ 